\title{
Open-label feasibility study of pazopanib, carboplatin, and paclitaxel in women with newly diagnosed, untreated, gynaecologic tumours: a phase I/II trial of the AGO study group
}

\author{
A du Bois*, I I Vergote ${ }^{2}$, P Wimberger ${ }^{3}$, I Ray-Coquard ${ }^{4}$, P Harter', LB Curtis ${ }^{5}$ and I Mitrica ${ }^{6}$ \\ 'Departments of Gynecology and Gynecologic Oncology, Kliniken Essen Mitte, Henricistrasse 92, 45136 Essen, Germany; ${ }^{2}$ Department of Gynecologic \\ Oncology, University Hospitals Leuven, Leuven, Belgium; ${ }^{3}$ Department of Gynecology and Obstetrics, University of Duisburg-Essen, Essen, Germany; \\ ${ }^{4}$ Centre Leon Bérard, Lyon, France; ${ }^{5}$ GlaxoSmithKline, Brentford, London, UK; ${ }^{6}$ GlaxoSmithKline, Research Triangle Park, NC, USA
}

\begin{abstract}
INTRODUCTION: Although most patients with advanced gynaecologic malignancies respond to first-line treatment with platinum-taxane doublets, a significant proportion of patients relapse. Combining targeted agents that have non-overlapping mechanisms of action with chemotherapy may potentially increase the disease-free interval. Accordingly, this study evaluated the feasibility of combining pazopanib, an oral angiogenesis inhibitor, with paclitaxel and carboplatin.

METHODS: This open-label, phase I/II study planned to evaluate the safety and efficacy of paclitaxel $175 \mathrm{mg} \mathrm{m}^{-2}$ plus carboplatin (AUC5 (Arm A) or AUC6 (Arm B)) once in every 3 weeks for up to six cycles with either 800 or 400 mg per day pazopanib. RESULTS: Dose-limiting toxicities (DLTs) were observed in two of the first six patients enrolled at pazopanib $800 \mathrm{mg}$ plus paclitaxel $175 \mathrm{mg} \mathrm{m}^{-2}$ plus carboplatin AUC5. Of the six patients enrolled in the next and lowest dosing level planned in the study, pazopanib $400 \mathrm{mg}$ plus paclitaxel $175 \mathrm{mg} \mathrm{m}^{-2}$ plus carboplatin AUC5, two patients also experienced DLTs and the study was terminated. Two of the 4 DLTs observed overall were gastrointestinal perforations. Severe myelotoxicity was reported in 6 of 12 patients. CONCLUSION: Combining either 800 or $400 \mathrm{mg}$ per day pazopanib with standard carboplatin/paclitaxel chemotherapy is not a feasible treatment option.

British Journal of Cancer (2012) 1 06, 629-632. doi:10.1038/bjc.201 I.608 www.bjcancer.com
\end{abstract}

Published online 12 January 2012

(c) 2012 Cancer Research UK

Keywords: ovarian cancer; pazopanib; phase I study

Platinum-taxane doublets are widely used as a standard first-line treatment for patients with advanced gynaecologic malignancies (du Bois et al, 2003; Greer et al, 2008; Morgan et al, 2008). However, a high proportion of patients eventually relapse. One of the clinical approaches to increase the duration of disease control has been to identify new agents with a non-overlapping mechanism of action and demonstrated single-agent antitumor activity to combine with platinum and paclitaxel.

Translational data suggest that angiogenesis has a critical role in the growth of ovarian tumours and is therefore a potentially viable therapeutic target (Yamamoto et al, 1997; Cooper et al, 2002). Thus, combining an active antiangiogenic agent with standard chemotherapy may potentially improve tumour control and provide sustained benefit. Indeed, this approach has been validated in controlled phase III trials in patients with advanced

\footnotetext{
*Correspondence: Professor A du Bois;

E-mail: prof.dubois@googlemail.com

Previous publication: AACR-NCl-EORTC International Conference on Molecular Targets and Cancer Therapeutics; November 15-19, 2009; Boston, MA. Abstract A6

Received 22 September 201 I; revised 16 December 201।; accepted 16 December 2011; published online 12 January 2012
}

solid tumours (Sandler et al, 2006; Reck et al, 2009). More recently, two phase III trials reported that adding bevacizumab to standard chemotherapy in women with newly diagnosed ovarian cancer significantly improved progression-free survival (Burger et al, 2010; Kristensen et al, 2011) and overall survival for a subgroup of patients with residual disease after initial surgery (Kristensen et al, 2011).

Pazopanib is an oral angiogenesis inhibitor targeting vascular endothelial growth factor receptors, platelet-derived growth factor receptors, and c-Kit (Sonpavde and Hutson, 2007) with demonstrated single-agent activity in renal cell carcinoma (Friedlander et al, 2010) and soft tissue sarcoma (Van Der Graaf et al, 2011). In addition, preliminary evidence of clinical activity associated with pazopanib has been observed in breast cancer (Taylor et al, 2010), thyroid tumours (Iwamoto et al, 2010), and gynaecologic tumours including recurrent ovarian disease (Friedlander et al, 2010) and cervical cancer (Monk et al, 2010). A maximum tolerated regimen for this combination had previously been identified in patients with solid tumours and up to three previous treatments as pazopanib $200 \mathrm{mg}$ daily with paclitaxel $175 \mathrm{mg} \mathrm{m}^{-2}$ and carboplatin at area under the curve 5 (AUC5) given every 3 weeks; however, the optimal dosing regimen was not established in this setting of untreated gynaecologic cancers using a short-term chemotherapy regimen. 
Accordingly, this phase I/II study (VEG110190; clinicaltrial.gov identifier NCT00561795) explored the feasibility of combining pazopanib with the standard regimen of paclitaxel and carboplatin as first-line treatment in patients with advanced gynaecologic tumours.

\section{PATIENTS AND METHODS}

\section{Patients}

This study enrolled adult women ( $\geqslant 18$ years of age) with newly diagnosed, measurable or non-measurable advanced gynaecologic tumours, for whom carboplatin-paclitaxel chemotherapy was indicated. Additional eligibility criteria included a performance status of 0 or 1 on the Eastern Cooperative Oncology Group (ECOG) scale and adequate major system/organ function.

\section{Study design, treatment, and assessment}

This open-label, phase I/II study explored the safety and tolerability of adding pazopanib to a standard combination of paclitaxel and carboplatin in patients with previously untreated, advanced gynaecologic tumours. It was planned that a minimum of 12 and a maximum of 46 women would be enrolled. The study planned to test two treatment arms: patients enrolled in arm A received paclitaxel $175 \mathrm{mg} \mathrm{m}^{-2}$ and carboplatin AUC5 every 3 weeks for up to 6 cycles plus daily pazopanib; if arm A was successful, patients enrolled in arm B would receive paclitaxel $175 \mathrm{mg} \mathrm{m}^{-2}$ and carboplatin AUC6 every 3 weeks for up to 6 cycles plus daily pazopanib. Within each arm, two dosing levels of pazopanib (800 and $400 \mathrm{mg}$ per day) were planned to be tested. Pazopanib dosing was started at $800 \mathrm{mg}$ per day, and if not adequately tolerated, could be reduced to $400 \mathrm{mg}$ per day for individual patients, or if necessary, reduced in the subsequent arm. Tolerability was assessed in accordance with standard, predefined clinical criteria for dose-limiting toxicity. Adverse events were graded according to Common Terminology Criteria for Adverse Events (version 3.0) and coded to the preferred term level using the Medical Dictionary for Regulatory Activities.

\section{Study objectives}

The primary objectives of the study were to develop a feasible dose and schedule, and to assess the safety and tolerability of combining pazopanib with standard carboplatin/paclitaxel chemotherapy in women with previously untreated, advanced gynaecologic cancers. Secondary objectives included evaluation of tumour response rate in patients with measurable disease, 18-week progression-free survival, and cancer antigen (CA-125) response rate in patients with elevated levels at baseline.

\section{RESULTS}

This study enrolled 12 Caucasian women with a mean age of 54 years (range 39-65 years) and ECOG performance status of 0 (eight patients; 67\%) or 1 (four patients; 33\%). The safety population included all 12 patients enrolled in arm A, all of whom received at least one dose of study medication.

\section{Feasibility/tolerability}

Of the six patients enrolled in the pazopanib $800 \mathrm{mg}$ (once daily) plus paclitaxel $175 \mathrm{mg} \mathrm{m}^{-2}$ and carboplatin AUC5 ( $\mathrm{q} 3$ weeks $\times$ six cycles for both) cohort, two patients experienced DLTs. These included grade 5 ileal perforation (one patient), which eventually led to death during the study, and grade 3 abdominal cramps (one patient), which led to dose reduction. The patient with ileal perforation had extensive tumour involvement of the small bowel mesentery, and a residual tumour $>2 \mathrm{~cm}$ in size after surgery. Accordingly, the dose of pazopanib was reduced to $400 \mathrm{mg}$ in the six additional patients enrolled and treated with paclitaxel $175 \mathrm{mg} \mathrm{m}^{-2}$ and carboplatin AUC5. However, two patients in this cohort also experienced DLTs, which included grade 4 intestinal perforation (one patient) and grade 2 skin necrosis (one patient), both leading to discontinuation of treatment. Per protocol, pazopanib was not further dose reduced, and arm B, which was to explore a combination regimen with a higher dose of carboplatin (AUC6), was not evaluated. The study was closed because of excessive toxicity, and a maximum tolerated regimen was not identified.

\section{Safety}

Overall, 10 of the 12 patients enrolled in this study discontinued treatment. Seven patients (58\%) discontinued because of treatment-related adverse events, and treatment for three patients was discontinued prematurely when the study closed. Myelotoxicity was the most common $\mathrm{AE}$ (Table 1) and the leading cause of treatment discontinuation. Overall, eight patients $(67 \%)$ experienced serious treatment-related adverse events, which included neutropenia in six patients $(50 \%)$ and gastrointestinal perforations in two patients $(17 \%)$.

\section{Efficacy}

Efficacy was not evaluated because of early treatment discontinuation in most patients and small patient numbers. No patients progressed on receiving study treatment.

\section{DISCUSSION}

Pazopanib $800 \mathrm{mg}$ once daily or $400 \mathrm{mg}$ once daily administered concurrently with standard paclitaxel and carboplatin chemotherapy is not a feasible regimen in patients with newly diagnosed gynaecologic malignancies, because of unacceptable toxicity. A pazopanib dose of $200 \mathrm{mg}$ once daily was not considered clinically meaningful because drug exposure would be subtherapeutic in many patients, and was therefore not further explored (Hurwitz et al, 2009). The high frequency and severity of toxicities reported in this study may be related to drug interactions between

Table I Summary of adverse events reported in $\geqslant 2$ patients in any arm

\begin{tabular}{|c|c|c|}
\hline \multirow[b]{2}{*}{$\begin{array}{l}\text { AEs regardless of } \\
\text { causality, } n(\%)\end{array}$} & \multicolumn{2}{|c|}{$\begin{array}{l}\text { Paclitaxel } 175 \mathrm{mg} \mathrm{m}^{-2} \text { plus } \\
\text { carboplatin AUC5 }\end{array}$} \\
\hline & $\begin{array}{c}\text { Pazopanib } \\
800 \mathrm{mg} \\
(n=6)\end{array}$ & $\begin{array}{c}\text { Pazopanib } \\
400 \mathrm{mg} \\
(n=6)\end{array}$ \\
\hline \multicolumn{3}{|l|}{ Haematologic } \\
\hline Neutropenia & $5(83)$ & $3(50)$ \\
\hline Thrombocytopenia & $3(50)$ & $1(17)$ \\
\hline Haemoglobin decreased & I (17) & $2(33)$ \\
\hline \multicolumn{3}{|l|}{ Nonhaematologic } \\
\hline Alopecia & $4(67)$ & $3(50)$ \\
\hline Fatigue & $4(67)$ & $4(67)$ \\
\hline Abdominal pain & $3(50)$ & $2(33)$ \\
\hline Nausea & $3(50)$ & $3(50)$ \\
\hline Nasopharyngitis & $3(50)$ & 0 \\
\hline Diarrhoea & $2(33)$ & $2(33)$ \\
\hline Vomiting & $2(33)$ & I (17) \\
\hline
\end{tabular}

Abbreviations: $\mathrm{AEs}=$ adverse events; $\mathrm{AUC}=$ area under the curve. 
pazopanib and paclitaxel and/or carboplatin that result in undesirably high levels of chemotherapy agents in patients. Indeed, a recent phase I study (VEG105427, Part 2) that evaluated this combination in patients with advanced solid tumours showed that pazopanib decreased the clearance of paclitaxel, increased the AUC of carboplatin, and increased maximum concentration $\left(C_{\max }\right)$ of both paclitaxel and carboplatin (Burris et al, 2009). Similar toxicity data have been reported in studies attempting to combine other antiangiogenic agents with a platinum-taxane doublet. For example, a phase II study of sorafenib in combination with paclitaxel $175 \mathrm{mg} \mathrm{m}^{-2}$ and carboplatin AUC5 was terminated because of excessive toxicities observed in the first four patients enrolled (Polcher et al, 2010). Likewise, a clinical trial exploring the addition of sunitinib to paclitaxel plus carboplatin chemotherapy concluded that this combination, although feasible, was difficult to administer (Heath et al, 2011). Had these safety issues and data on potential pharmacokinetic interaction been known at the time of design or conduct of the current study, a formal phase I dose-escalation study with a dense pharmacokinetic sampling schedule would have been considered as an alternative to the current phase I/II study.

Pazopanib and other antiangiogenic agents have demonstrated single-agent antitumor activity in multiple tumour types (Sleijfer et al, 2009; Altorki et al, 2010; Friedlander et al, 2010; Sternberg et al, 2010) and have shown preliminary evidence of antitumor activity in gynaecologic tumours (Friedlander et al, 2010). Although it may not be feasible to combine some of these agents with standard chemotherapy, the potential remains to increase the duration of disease-free survival by using these agents as a consolidation/maintenance monotherapy after tumour control has been achieved with standard treatment modalities. Indeed, in the recent report of the phase III GOG 0218 and ICON7 trials, the addition of adjuvant bevacizumab to chemotherapy plus bevacizumab consolidation significantly improved progression-free survival compared with chemotherapy alone or chemotherapy plus bevacizumab (Burger et al, 2010; Kristensen et al, 2011). Accordingly, an ongoing phase III, placebo-controlled trial led by Arbeitsgemeinschaft Gynäkologische Onkologie (AGO) is exploring the benefit of 24 months of pazopanib monotherapy in the maintenance setting in patients with stage II-IV ovarian disease without disease progression after first-line chemotherapy (AGOOVAR16; clinicaltrials.gov identifier NCT00866697). This

\section{REFERENCES}

Altorki N, Lane ME, Bauer T, Lee PC, Guarino MJ, Pass H, Felip E, Peylan-Ramu N, Gurpide A, Grannis FW, Mitchell JD, Tachdjian S, Swann RS, Huff A, Roychowdhury DF, Reeves A, Ottesen LH, Yankelevitz DF (2010) Phase II proof-of-concept study of pazopanib monotherapy in treatment-naive patients with stage I/II resectable non-small-cell lung cancer. J Clin Oncol 28(19): 3131-3137

Burger RA, Brady MF, Bookman MA, Walker JL, Homesley HD, Fowler J, Monk BJ, Greer BE, Boente M, Liang SX (2010) Phase III trial of bevacizumab (BEV) in the primary treatment of advanced epithelial ovarian cancer (EOC), primary peritoneal cancer (PPC), or fallopian tube cancer (FTC): a Gynecologic Oncology Group study. J Clin Oncol 28(18s): $18 \mathrm{~s}$, (abstract LBA1)

Burris H, Du Bois A, Dowlati A, Gainer S, Park J, Stutts M, Dar M, Suttle B, Mitrica I, Tan AR (2009) Pazopanib combination with paclitaxel and carboplatin in patients with advanced solid tumors and gynecological cancers: results of two phase I studies. Mol Cancer Ther 8(12): (abstract A6)

Cooper BC, Ritchie JM, Broghammer CL, Coffin J, Sorosky JI, Buller RE, Hendrix MJ, Sood AK (2002) Preoperative serum vascular endothelial growth factor levels: significance in ovarian cancer. Clin Cancer Res 8(10): $3193-3197$

du Bois A, Luck HJ, Meier W, Adams HP, Mobus V, Costa S, Bauknecht T, Richter B, Warm M, Schroder W, Olbricht S, Nitz U, Jackisch C, Emons G, Wagner U, Kuhn W, Pfisterer J (2003) A randomized clinical trial of trial has already reached full recruitment with 900 patients, and results are awaited. In addition, combinations of other pazopanib regimens (e.g., intermittent) with other chemotherapy regimens (e.g., weekly carboplatin and/or paclitaxel) could still be feasible and are currently being tested in clinical studies (Harter and Marth, 2011; National Cancer Institute, 2011).

\section{ACKNOWLEDGEMENTS}

Financial support for medical editorial assistance was provided by GlaxoSmithKline. We thank the patients and their families and all investigators who participated in this trial. We acknowledge Jerome F Sah, PhD, ProEd Communications, Inc., for his medical editorial assistance with this manuscript.

\section{Conflict of Interest}

Andreas du Bois received honoraria for educational activities from GSK, Roche, PharmaMar, Schering Plough, Novartis, and Astra Zeneca. In addition, Andreas du Bois has participated in advisory boards and has received financial compensation from Astra Zeneca, Roche, PharmaMar, Johnson \& Johnson, Schering Plough, and Amgen. Ignace Vergote has been a consultant, received travel funding, and/or received grants from Algeta, Amgen NV, AstraZeneca, Boehringer-Ingelheim, BristolMyers Squibb, Eli Lilly, Fresenius, GE Healthcare, GlaxoSmithKline, Janssen-Cilag, Menarini Ricerche, Merck Sharp \& Dohme, Morphotek, Nektar Therapeutics, Novo Nordisk Pharmaceutical Industries, Oasmia Pharmaceutical, PharmaMar, HoffmannLaRoche, Sanofi-Aventis, Schering-Plough, Sigma Tau Pharmaceuticals, and Telik. Pauline Wimberger received honoraria for educational activities from GlaxoSmithKline, Roche, PharmaMar, and Schering-Plough. Isabelle Ray-Coquard received honoraria for educational activities from Roche, PharmaMar, Schering-Plough, Novartis, and Astra Zeneca. In addition, Isabelle Ray-Coquard has participated in advisory boards and has received financial compensation from Roche, PharmaMar, Johnson \& Johnson, Schering-Plough, and Abbott. Laurie Baylor Curtis and Ionel Mitrica are employed by GlaxoSmithKline. Philipp Harter declare no conflict of interest. cisplatin/paclitaxel versus carboplatin/paclitaxel as first-line treatment of ovarian cancer. J Natl Cancer Inst 95(17): 1320-1329

Friedlander M, Hancock KC, Rischin D, Messing MJ, Stringer CA, Matthys GM, Ma B, Hodge JP, Lager JJ (2010) A Phase II, open-label study evaluating pazopanib in patients with recurrent ovarian cancer. Gynecol Oncol 119(1): $32-37$

Greer BE, Koh WJ, Abu-Rustum N, Bookman MA, Bristow RE, Campos S, Cho KR, Copeland L, Eifel P, Huh WK, Jaggernauth W, Kapp DS, Kavanagh J, Lipscomb GH, Lurain III JR, Morgan M, Morgan Jr RJ, Powell CB, Remmenga SW, Reynolds RK, Secord AA, Small Jr W, Teng N (2008) Cervical cancer. J Natl Compr Canc Netw 6(1): 14-36

Harter P, Marth C (2011) Gynecologic Cancer Intergroup Ovarian Cancer Committee report [slide presentation]. Presented at: GCIG Autumn Meeting; 8-9 September 2011; Milan, Italy. Available at: http:// www.gcig.igcs.org/files/OvarianGAReport(1).ppt (accessed 19 September 2011)

Heath EI, Blumenschein Jr GR, Cohen RB, Lorusso PM, Loconte NK, Kim ST, Ruiz-Garcia A, Chao RC, Wilding G (2011) Sunitinib in combination with paclitaxel plus carboplatin in patients with advanced solid tumors: phase I study results. Cancer Chemother Pharmacol 68(3): 703-712

Hurwitz HI, Dowlati A, Saini S, Savage S, Suttle AB, Gibson DM, Hodge JP, Merkle EM, Pandite L (2009) Phase I trial of pazopanib in patients with advanced cancer. Clin Cancer Res 15(12): 4220-4227 
Iwamoto FM, Lamborn KR, Robins HI, Mehta MP, Chang SM, Butowski NA, Deangelis LM, Abrey LE, Zhang WT, Prados MD, Fine HA (2010) Phase II trial of pazopanib (GW786034), an oral multi-targeted angiogenesis inhibitor, for adults with recurrent glioblastoma (North American Brain Tumor Consortium Study 06-02). Neuro Oncol 12(8): $855-861$

Kristensen G, Perren T, Qian W, Pfisterer J, Ledermann JA, Joly F, Carey MS, Beale PJ, Cervantes A, Oza AM, GCIG (2011) Result of interim analysis of overall survival in the GCIG ICON7 phase III randomized trial of bevacizumab in women with newly diagnosed ovarian cancer. J Clin Oncol 29(Suppl): (abstract LBA5006)

Monk BJ, Mas Lopez L, Zarba JJ, Oaknin A, Tarpin C, Termrungruanglert W, Alber JA, Ding J, Stutts MW, Pandite LN (2010) Phase II, open-label study of pazopanib or lapatinib monotherapy compared with pazopanib plus lapatinib combination therapy in patients with advanced and recurrent cervical cancer. J Clin Oncol 28(22): 3562-3569

Morgan Jr RJ, Alvarez RD, Armstrong DK, Boston B, Chen LM, Copeland L, Fowler J, Gaffney DK, Gershenson D, Greer BE, Grigsby PW, Havrilesky LJ, Johnston C, Lancaster JM, Lele S, Matulonis U, O’Malley D, Ozols RF, Remmenga SW, Sabbatini P, Schink J, Teng N (2008) Ovarian cancer. Clinical practice guidelines in oncology. J Natl Compr Canc Netw 6(8): $766-794$

National Cancer Institute (2011) Pazopanib hydrochloride, paclitaxel, and carboplatin in treating patients with refractory or resistant ovarian epithelial cancer, fallopian tube cancer, or peritoneal cancer. Available at: http://clinicaltrials.gov/ct2/show/NCT01402271?term $=$ EORTC+55092 \&rank $=1$ (Accessed on 19 September 2011)

Polcher M, Eckhardt M, Coch C, Wolfgarten M, Kubler K, Hartmann G, Kuhn W, Rudlowski C (2010) Sorafenib in combination with carboplatin and paclitaxel as neoadjuvant chemotherapy in patients with advanced ovarian cancer. Cancer Chemother Pharmacol 66(1): 203-207

Reck M, von Pawel J, Zatloukal P, Ramlau R, Gorbounova V, Hirsh V, Leighl N, Mezger J, Archer V, Moore N, Manegold C (2009) Phase III trial of cisplatin plus gemcitabine with either placebo or bevacizumab as first-line therapy for nonsquamous non-small-cell lung cancer: AVAil. J Clin Oncol 27(8): 1227-1234
Sandler A, Gray R, Perry MC, Brahmer J, Schiller JH, Dowlati A, Lilenbaum R, Johnson DH (2006) Paclitaxel-carboplatin alone or with bevacizumab for non-small-cell lung cancer. $N$ Engl J Med 355(24): $2542-2550$

Sleijfer S, Ray-Coquard I, Papai Z, Le Cesne A, Scurr M, Schoffski P, Collin F, Pandite L, Marreaud S, De Brauwer A, van Glabbeke M, Verweij J, Blay JY (2009) Pazopanib, a multikinase angiogenesis inhibitor, in patients with relapsed or refractory advanced soft tissue sarcoma: a phase II study from the European organisation for research and treatment of cancersoft tissue and bone sarcoma group (EORTC study 62043). J Clin Oncol 27(19): $3126-3132$

Sonpavde G, Hutson TE (2007) Pazopanib: a novel multitargeted tyrosine kinase inhibitor. Curr Oncol Rep 9(2): 115-119

Sternberg CN, Davis ID, Mardiak J, Szczylik C, Lee E, Wagstaff J, Barrios $\mathrm{CH}$, Salman P, Gladkov OA, Kavina A, Zarba JJ, Chen M, McCann L, Pandite L, Roychowdhury DF, Hawkins RE (2010) Pazopanib in locally advanced or metastatic renal cell carcinoma: results of a randomized phase III trial. J Clin Oncol 28(6): $1061-1068$

Taylor SK, Chia S, Dent S, Clemons M, Agulnik M, Grenci P, Wang L, Oza AM, Ivy P, Pritchard KI, Leighl NB (2010) A phase II study of pazopanib in patients with recurrent or metastatic invasive breast carcinoma: a tria of the Princess Margaret Hospital phase II consortium. Oncologist 15(8): $810-818$

Van Der Graaf WT, Blay J, Chawla SP, Kim D, Bui Nguyen B, Casali PG, Schöffski P, Aglietta M, Staddon AP, Beppu Y, Le Cesne A Gelderblom H, Judson IR, Araki N, Ouali M, Marreaud S, Hodge R, Dewji M, Dei Tos AP, Hohenberger P (2011) PALETTE: a randomized, double-blind, phase III trial of pazopanib versus placebo in patients (pts) with soft-tissue sarcoma (STS) whose disease has progressed during or following prior chemotherapy-An EORTC STBSG Global Network Study (EORTC 62072). J Clin Oncol 29(suppl): (abstract LBA10002)

Yamamoto S, Konishi I, Mandai M, Kuroda H, Komatsu T, Nanbu K, Sakahara H, Mori T (1997) Expression of vascular endothelial growth factor (VEGF) in epithelial ovarian neoplasms: correlation with clinicopathology and patient survival, and analysis of serum VEGF levels. Br J Cancer 76(9): 1221-1227

This work is published under the standard license to publish agreement. After 12 months the work will become freely available and the license terms will switch to a Creative Commons Attribution-NonCommercial-Share Alike 3.0 Unported License. 